\title{
The earliest history of diaphragm physiology
}

\author{
J-Ph. Derenne*, A. Debru**, A.E. Grassino+, W.A. Whitelaw ${ }^{++}$
}

\begin{abstract}
The earliest history of diaphragm physiology. J-Ph. Derenne, A. Debru, A.E. Grassino, W.A. Whitelaw. CERS Journals Ltd 1994.

ABSTRACT: The diaphragm was recognized as a distinct anatomical structure in the earliest Greek writings. However, the precise description of wounds suffered by warriors during the Trojan war by Homer was not tied to any particular function. The diaphragm was assimilated to the region that harbours thought. The first physiologic explanations of respiration by Empedocles in the 5th century BC and the concepts introduced by Plato and Hippocrates did not include a significant participation of the diaphragm. Aristole was the first to link respiration to a particular organ and a specific movement of the thorax. However, he considered that it was the heart which caused the lungs to expand by heating them, and the lungs in turn forced the thorax to dilate, a concept which was to survive until the 17th century. As in Aristole's theory the diaphragm played no role in respiration and was just a fence separating the thorax from the abdomen. A major break through occurred in Alexandria in the 4th and 3rd century BC: Herophilus was the first to recognize that muscles were the agents of movement and Erasistratus performed animal experiments which showed that the respiratory muscles were the agents of respiratory movements, thus opening the way to the later discoveries of Galen.
\end{abstract}

Eur Respir J., 1994, 7, 2234-2240.

\author{
*Service de Pneumologie, Groupe Hospitalier \\ Pitié-Salpêtrière, Paris, France. **Université \\ Charles de Gaulle-Lille III, Département \\ Langues Anciennes, Villeneuve d'Ascq, \\ France. +Université de Montreal and Meakins \\ Christie Laboratories, Montréal, Quebec, \\ Canada. ++Dept of Medicine, University \\ of Calgary, Calgary, Alberta, Canada. \\ Correspondence: J-Ph. Derenne \\ Service de Pneumologie \\ Groupe Hospitalier Pitié-Salpêtrière \\ 47, boulevard de l'Hôpital \\ 75651 Paris Cédex 13 \\ France
}

Keywords: Diaphragm, Greek philosophers, history of medicine, respiratory muscles

Received: February 91994

Accepted after revision August 201994
A time-travelling Aristotle or Galen, here to learn the modern answer to their old question of why we breathe, would have tremendous difficulty in understanding the new science and language of biochemistry and thermodynamics, just as we find it nearly impossible to guess what they had in mind with their concepts of innate heat, the mysterious substance called pneuma, and harmony between the elements. By contrast, we would be quite startled to find what little trouble the Greeks had in understanding the modern science of how we breathe. They would be very familiar with many basic questions that we are still investigating, such as which muscles are responsible for respiratory movements, what their individual contributions are, how they interact, and how they move the lungs and chest wall.

The similarity between our questions and those of the earliest physiologists makes it relatively easy to follow ideas about the diaphragm back to very ancient times, but the study is not without difficulty. The historical record has major gaps. We hear of teachers who were influential but did not write, and of important writings that have been permanently lost. What we can learn about many ancient scientists is second or third hand, transmitted by enthusiastic followers, sarcastic opponents or inaccurate summarizers, who selected, distorted or corrupted the originals. The texts we have are often fragmentary, and can present major problems to philologists, who debate the exact meaning of key words and sentences. Many of the ideas that might be spun together, retrospectively, into a thread of apparent progress were, in fact, hotly debated for centuries and never widely accepted. Therefore, even though it is clear that the diaphragm held an important place in the thinking of the ancient Greeks, and much was written about it, we cannot expect to have a really accurate appraisal of their concepts, or of how they developed.

The diaphragm was recognized as a distinct anatomical structure in the earliest Greek writings. To attract their attention to the subject, however, the ancient physiologists had to have the conviction that the diaphragm was very important, from which sprang the drive to understand its function. To begin asking relevant questions, they needed some other physiological concepts: of respiration as a vital process, of muscle as a contractile force-generating element, and of nerves as the pathway for activating muscle. They also needed some concepts of physics to use in the explanation of movement.

The early history of diaphragm physiology is, thus, tied closely to the development of anatomy, comparative zoology, experimental physiology, medicine, physics, and philosophy. By the time of the Roman Empire, progress in all these disciplines enabled the Greeks to reach a surprisingly complete and modern comprehension of the respiratory pump. Almost all of it was lost over the next few hundred years. In fact, it seems to be the curious fate of the respiratory muscles that knowledge about them is repeatedly lost, only to be rediscovered many years or centuries afterwards. 
Table 1. - Major contributors to the understanding of respiration and function of the diaphragm in early occidental literature

\begin{tabular}{lr}
\hline Homer & 9th C BC \\
Pythagoras & 6 th C BC \\
Empedocles & $500-430 \mathrm{BC}$ \\
Pericles & $495-429 \mathrm{BC}$ \\
Sophocles & $496-406 \mathrm{BC}$ \\
Herodotus & $484-425 \mathrm{BC}$ \\
Socrates & $469-399 \mathrm{BC}$ \\
Democritus & $460-362 \mathrm{BC}$ \\
Hippocrates & $460-359 \mathrm{BC}$ \\
Aristophanes & $448-380 \mathrm{BC}$ \\
Plato & $427-327 \mathrm{BC}$ \\
Aristole & $384-322 \mathrm{BC}$ \\
Herophilus & $\sim 300 \mathrm{BC}$ \\
Erasistratus & $3 \mathrm{rd}$ C BC \\
Celsus & 1 st C AD \\
Asclepiades & 1 st C AD \\
Rufus of Ephesus & $\sim 100 \mathrm{AD}$ \\
Marinus & $\sim 100 \mathrm{AD}$ \\
Quintus & $\sim 125 \mathrm{AD}$ \\
Numisianus & $2 \mathrm{nd} \mathrm{C} \mathrm{AD}$ \\
Lycus & \\
Satyrus & \\
Pelops & \\
Galen & $130-200 \mathrm{AD}$ \\
\hline
\end{tabular}

In this article and the one that follows in a subsequent issue of The Journal, we try to trace the origin and development of concepts about the diaphragm from its first recognition as an entity up to the synthesis made by Galen during the height of the Roman Empire. Some of the material was previously reviewed by CAMPBELL in the now out-of-print first edition of his book "The Respiratory Muscles and mechanics of breathing" [1]. The names of philosophers and scientists who introduced or developed significant concepts in this field before Galen are listed in table 1.

\section{The early Greeks}

The ancient Greeks cannot have been the first to recognize that breathing is a vital process, but they were the first to record their curiosity about the purpose of parts of the body and to develop theories to explain normal function and disease. Other ancient civilisations left no trace of a similar preoccupation with these biological questions.

Homer, in the 9th century $\mathrm{BC}$, gives us the oldest remaining record of Greek ideas about the human body. He describes, with astonishing precision, wounds suffered by Greeks and Trojans on the field of battle, using words which designate the respiratory and digestive system, larynx, trachea, bronchi, lungs and thorax, but he does not tie these anatomical observations to any particular concepts about the function of organs.

Noting that, when breathing stops, death follows shortly after and that new life begins with the first breath, the early Greeks, like other Indo-European peoples, built into their language the idea of "vital breath", and linked it to words for nature, the wind and the coolness of air [2]. (Psyche, the Greek word for soul or spirit, is related to ideas of ventilation and cooling). They thought life depended on an exchange between the exterior of the body and the interior, but did not dwell on the mechanism for moving air in and out. Far from being considered a muscle of respiration, the diaphragm was more or less assimilated into the region of the body that harbours thoughts. The meaning of the word "phren" itself is imprecise; it designates not only the diaphragm but also the pericardium or the lung. Thoughts took their name (phrenes) from their supposed location. Muscles were not imagined to have anything to do with movement. They were just one kind of flesh, somewhat different from liver in their consistency and edibility.

The first physiological explanations for respiration were offered by the pre-Socratic philosophers of the 6th and early 5th centuries BC. In this era, Empedocles, who lived in the Greek city-state of Agrigentum on the south coast of Sicily from about 490 to $430 \mathrm{BC}$, was the most interested in the phenomena of life, other philosophers being mainly occupied with problems of cosmology, astronomy and meteorology. The long and famous poems, "On the Nature of Being" and "Purifications", summarized his thoughts in a realm that combined medicine, science, philosophy and religion. His basic ideas of physiology seem to have been a refinement and extension of those developed by the school at Cortona, in Italy, on principles descended from those of Pythagoras. Empedocles's theory divided matter into four elements, earth, air, fire and water, the movements of which were governed by two principles resembling forces: "love" responsible for attraction and "hate" responsible for repulsion. Like-matter attracted like. All matter was endowed with multiple, tiny pores or channels, so that elements could interpenetrate. Variations in the size of the channels explained phenomena, such as how light could pass through transparent solids whilst air could not. His general concepts about physics seem to have been derived from his understanding of physiology [3]. Respiration was one of the keys to the origin of life, because it featured an exchange between the elements.

Aristotle passed on to us the 25 lines of poetry [4] that contain most of what we know of Empedocles's theory of respiration and of which interpretation has been the subject of much learned discussion [5-7]. In this fragment, he described respiration as inward and outward movement of air through small pores in the skin. To explain the mechanism he compared it to that of a clepsydra (fig. 1), a closed container with some small holes in the bottom and one small hole in the top, that was used to transport liquid from one vessel to another. When the bottom part was plunged into water with the hole at the top occluded by a thumb, water would not enter. Once the thumb was removed, the vessel would fill with water, but then the hole at the top could be closed and the clepsydra lifted out of the water with its contents. Water would now run out the bottom holes only when the thumb was removed again. The physical principles that compelled these movements were two: a natural tendency for water to occupy its own territory below the 

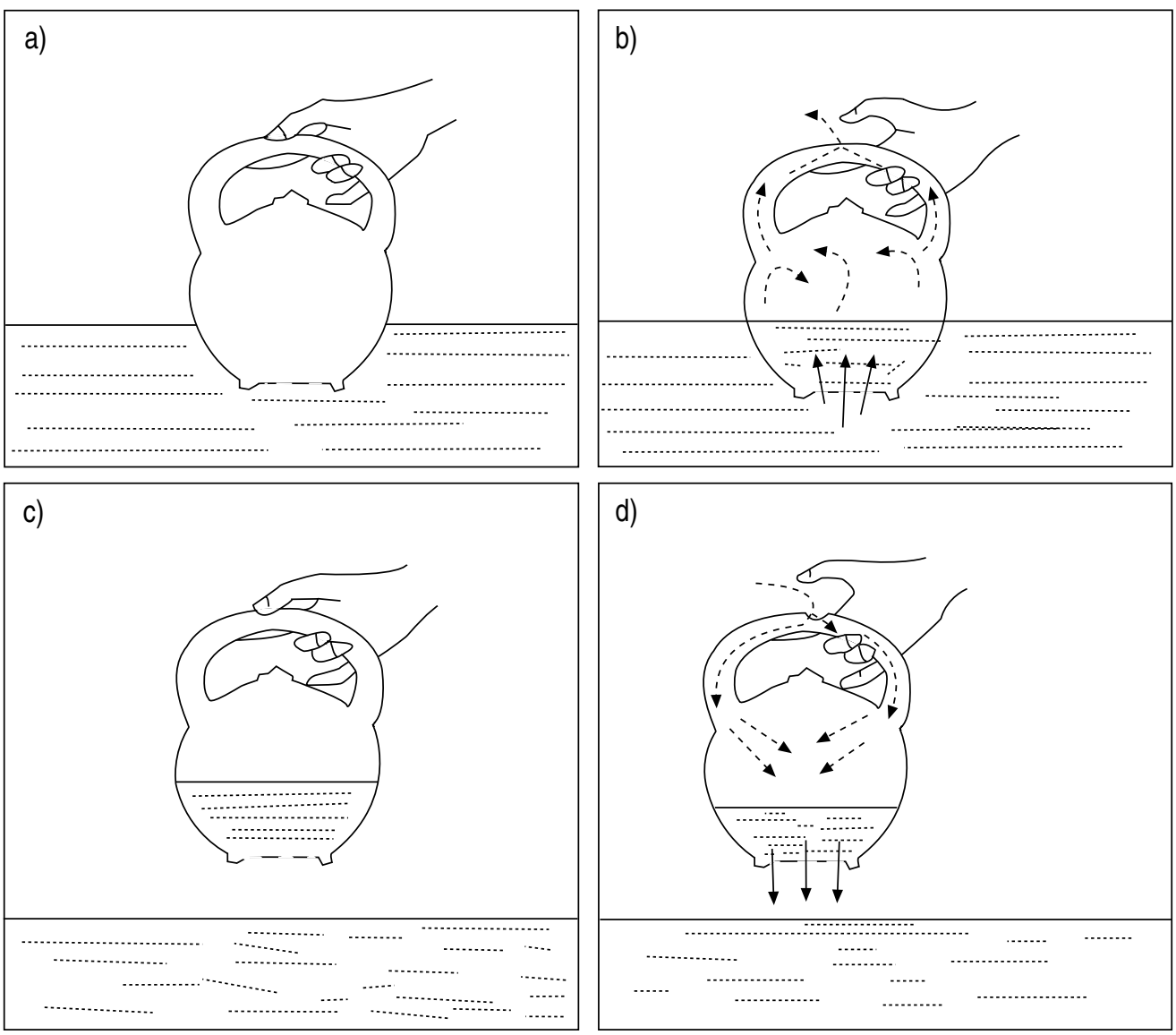

Fig. 1. - The clepsydra of Empedocles. The first "model" used to explain the mechanics of breathing.

water surface (fig. 1a and b), and a tendency for it to join the larger body of water from which the clepsydra had drawn it (fig. 1c and d). There is a complementary tendency of air to enter a space within its own territory above the water surface (fig. 1c and d), and to be drawn toward the greater body of air (fig. 1a and b).

It seems logical that the water in this analogy should correspond to blood in the body. The holes in the bottom of the clepsydra clearly correspond to pores in the skin. The hole in the handle may very well represent the nose and mouth [6]. Blood in the body was initially supposed to be drawn outward through pores in the skin by the attraction of its major constituent, fire, toward the great body of fire in the cosmos. Presumably this attraction lessened as the fire was cooled when it neared the surface, the balance then being tipped in favour of the earth and water constituents of blood, which were drawn inward. The ebb and flow of blood in the proximal part of pores through the skin entrained an ebb and flow of air in the distal part, as in the clepsydra. Although this analogy does not draw on any concepts of pressure and volume that we would recognize, it was clear that the movement of air for respiration was directly caused by movement of blood in vessels.

The clepsydra is one of the first examples of a "model" used to explain a physiological process. A clear, concrete image described in beautiful poetry, with a mechanism easy to understand in the context of the physics of the day, it captivated minds and had a huge and lasting influence in spite of a lack of data and of a clear biological analogy. The ebb and flow of blood in pores cannot have been observed; the counterpart in physiology to the hand that regulates flow in the clepsydra was quite obscure.

We are not sure about Empedocles's views of breathing through the nose and mouth, except from the point of view of embryology and the "first breath". It had long been held that the first breath was generated internally by the warmth of the sperm and had to spring out, creating the air passages on its way and obliging the first respiratory movement to be expiration. The normal respiratory cycle was accordingly described as expiration followed by inspiration. After the exit of the first breath, the internal heat of the body attracted cold air to cool itself (or to nourish itself, according to certain philosophers), and, thus, provided the mechanism of inspiration.

In addition to philosophy and state politics, Empedocles practised medicine, like many devotees of respiratory physiology throughout history, but the link between his physician's art and his physiological theories is not clear. He was said to be an excellent doctor, who gloried in a traditional style that depended greatly on magic, even going so far as to declare himself a demigod. 
The concept of alternating repulsion and attraction between elements is dominant in Plato's dialogue, the Timaeus, a crucial reference point in the history of ancient thought. The protagonist, Timaeus, held the mechanism of respiration to be a circular impulsion of the elements, air and fire, which pass throughout the body along a lattice-work of conduits [8]. In many ways, this theory resembles that of Empedocles. Fire contained in vessels is attracted toward its like, outside the body. When it moves towards the mouth and nose, it pushes air ahead of it, and the air coming out pushes other air around and into the body through pores in the skin. Then, the warmed air outside cools, and the cool air inside warms up; this changes the balance of attractions and reverses the process, air rushing out of the pores and pushing air ahead of it back in through the mouth and nose. The need for circular motion stemmed from Timaeus's acceptance of a controversial tenet of the physics of the time: that there could never be a void. Nothing could move unless the object beside it moved to make way, and objects could not expand or contract to occupy space. In such a system, it was easiest to understand circular motion where everything moved at once, each part occupying the space left by the part ahead of it in the circle. The originality of Plato's model was to combine oral and cutaneous respiration into the same system. It also had the advantage of explaining the permanence of respiratory movement and integrating the idea of a cycle of cold and warmth.

In this system, there was obviously no need for the diaphragm to generate respiratory movement. Instead, it had a very important metaphysical function: to separate parts of the soul [9]. The uppermost, immortal soul, responsible for reason and judgement, was kept safely in the head, protected from too strong an influence of the other souls by the isthmus of the neck. The lower soul was divided into a better and a worse part. The better part, which partakes in courage and spirit, was placed in the chest, closer to the seat of reason in the head, in order to be better influenced by it and, thus, help to subdue the worse part. The heart was strategically placed to communicate directions from the better part of the mortal soul to the rest of the body through the vessels. The lungs were positioned to act as cooling cushions for the heart, in case it should become overactive and overheated when excited by passion. The worse part of the lower soul, subject to appetites for food and drink and all the other wants that are due to the nature of the body, was separated off by the diaphragm into the lower compartment, "as though it were a creature which though savage they must necessarily keep joined to the rest and feed" [9]. Indeed, the word "diaphragm" or "barrier" comes from the verb meaning to block or obstruct.

At about the same time as Plato taught in Athens, doctors of the school of Hippocrates were establishing the basis for scientific enquiry in medicine. One of their great strengths was minute and careful examination of patients. They knew that respiration was extremely important. Their case histories often describe breathing as fast or slow, deep or shallow, free or laboured [10], and they even make reference to periodic breathing [11, 12]. Some of them practised direct auscultation of the chest with succussion for localizing collections of fluid [13], and described rales and friction rubs. They also did surgical operations that amazed Laënnec. One treatise gives exact details of when and how to drain water or pus from the chest: how to locate the collection, prepare the patient, incise with a scalpel or cauterize with a hot wire, leave a flax-seton (a heavy thread that acts as a drain) in the wound, and not let the fluid run out too rapidly. Another describes how to treat painful pleurisy by making an artificial pneumothorax, using a bladder connected to a cannula introduced between the ribs [14]. These clinical observations must have provoked questions about physiology.

Conceptually, they made a complete break with the past by rejecting intervention of the gods as an explanation for disease, insisting on natural explanations instead. A famous example was the high incidence of impotence among Scythian men. Herodotus blamed it on Aphrodite taking revenge for the long-ago pillage of her temple by Scythians, but Hippocrates [15] attributed it to excessive horseback riding causing a disturbance of the organs that carry semen. (The argument is an epidemiological one: if impotence had a divine cause, it ought to be commonest in poor Scythians, who cannot afford sacrifices to the gods. But, in fact, it troubles mainly the rich [16]). Everything that is observed in patients must have a natural cause, and understanding these causes is essential to physicians who want to know the correct remedy. These convictions, which still drive the search for knowledge about body mechanisms were clearly formulated by Hippocrates [16].

When it came to the diaphragm or any other internal workings of the body, the Hippocratic physicians had very little data and made do with rather fanciful ideas. They did no human dissection, and could learn internal anatomy only crudely, either from animal sacrifices with inspection of the organs for augury, or from experience with wounds and surgery, or from animal dissections [16]. They never mentioned the lungs in connection with breathing. The author of the treatise "On the Sacred Disease" proposed instead that air breathed in goes first to the brain, then to the heart and the other parts of the body [17]. They did know grossly where the heart, liver, spleen, intestines, kidneys and organs of generation were found, and the diaphragm is prominent on the brief list of structures that are frequently mentioned. Its attachments to the spine and the apertures for great vessels were noted [18, 19]. In a famous passage, one writer explicitly rejected the old idea that the diaphragm might be the centre of thought and sensation: "Wherefore, I say, that it is the brain which interprets the understanding. But the diaphragm has obtained its name ( $\varphi \rho \varepsilon v \varepsilon \sigma)$ from accident and usage, (this refers to the fact that $\varphi \rho \varepsilon v$ is the word for "mind"), and not from reality or nature, for I know no power which it possesses, either as to sense or understanding, except that when the man is affected with unexpected joy or sorrow, it throbs and produces palpitations, owing to its thinness, and as having no belly to receive anything good or bad that 
may present themselves to it, but it is thrown into commotion by both these, from its natural weakness" [17]. He presented arguments to support this view, but none that we would find convincing.

The role of the diaphragm in respiration was bound to remain obscure, because there was as yet no concept of muscle as an agent of movement. Instead, the diaphragm served mainly as a partition that separated both two major cavities of the body and two major categories of disease, which deserved quite different approaches to treatment. Thus, "respiration when frequent, indicates pain or inflammation above the diaphragm" [20]; and "pains seated above the diaphragm indicate purging upwards and those below, downwards" [21].

Insisting on a natural explanation for the distribution of abscesses near the diaphragm, the author of "On Ancient Medicine" proposed a theory that makes little sense to modern physiologists, but shows the concepts used at the time [22]. Overly strong juices or vapours that rush about in the abdomen interact with the various organs according to their structure and consistency. The stomach and bowels open to accommodate the juices or gases comfortably; the bladder is impenetrable to them and seldom bothered; the liver is most susceptible because of its consistency - soft enough to admit the noxious material but firm enough to react against it, leading to pain and suppuration or abscess. The diaphragm is also susceptible to pain and abscess formation, but less so than the liver, because it is stronger and more resistant. Many of our own firmly held but not fully tested beliefs may seem equally strange a thousand years from now. To their everlasting credit, the Hippocratic authors were first to affirm that medical knowledge would improve as time went on, and, thus, conceived both the progress of science and the humility of scientists.

\section{The contribution of Aristotle}

It was Aristotle who first linked respiration to a particular organ and a specific movement of the thorax. His contributions made a great turning point in the history of physiology, due to the conjunction of two things: the new importance given to anatomy and the use of the concept of a "final cause" or purpose. The son of a physician, Aristotle devoted much of his life to the study of biology. He was a pioneer in natural history, made a tremendous series of painstaking and accurate observations of biological phenomena, and was the first to illustrate a book in biology [23]. Among his most celebrated works in this field are the "History of Animals" (i.e. investigations into living beings), the "Parts of Animals", and some small treatises on natural history, including one called "On Respiration". In the latter work, he vigorously criticized the theories of Empedocles, Plato and others, on the ground that they failed to explain the function of respiration. For Aristotle it was essential to know not only the use of respiration but also the "mechanism" for it.

He maintained that the "use" of respiration was to cool the innate heat of the body and keep it from becoming excessive. The innate heat could be destroyed by extinction, through meeting with excessive cold, or by exhaustion, if the heat was too great for the supply of fuel. The analogy was that of a charcoal fire, which will go out if it is not supplied with a constant draft of cool air, even though there is plenty of fuel [7].

Because of the explanation he gave for the "mechanism" of breathing, modern partisans of the respiratory system may blame Aristotle for the pernicious and enduring misconception of western culture, that the heart is more important than the respiratory pump. He argued from his studies in comparative zoology that the lungs were involved in breathing, because they were found in all animals that breathed and only in those animals. (For other animals cooling of the inner heat was achieved by various other means). But in his "cardiocentric" theory, the heart was the site of the innate heat, acted as the respiratory organ by attracting cool air, and contained pneuma (or breath) [24]. The heart caused the lungs to expand by heating them, and the lungs in turn forced the thorax to dilate. The lung "receives the principle of movement from the heart and offers a large space to the incoming air because of its spongy nature and because of its size. In fact, when it dilates the air comes in, and when it contracts the air goes out" [25]. The lung did not expand according to Charles' law for gases, however. Its receptacle expanded because of the heat and, in so doing, created more space within itself which was then filled by incoming cool air. Cooling caused the lungs to shrink again. Air went in and out as in a bellows, and the thorax moved only because the lungs moved. This view was to persist until after William Harvey's time, resistant to multiple refutations provided in experiments conducted by supporters of the respiratory muscle theory.

In Aristotle's theory, the diaphragm has no role in respiration, although it is quite precisely described. It continues to be important for separating the upper part (the better) from the lower part (which exists only for the benefit of the other part), although the purpose seems to be shifting from a metaphysical one towards a physiological one. And, it continues to have an important proximity to the region that harbours thoughts and emotions [26, 27].

"Whenever, owing to their proximity, (the fleshy parts of the diaphragm) draw up the hot residual fluid, this at once causes a recognizable disturbance of the intelligence and of sensation. And that is why they are called phrenes: as if they took a part in the act of thinking. This of course they do not do; but their proximity to those organs which do so take part makes the change of condition in the intelligence recognizable. Another indication that it is when heated that they quickly make the sensation recognizable is afforded by what happens when we laugh. When people are tickled, they quickly burst into laughter, and this is because the motion quickly penetrates to this part, and even though it is only gently warmed, still it produces a movement in the intelligence which is recognizable" [28]. 
Aristotle gave a clinical example that was known to Hippocrates: "war wounds in the region of the diaphragm provoke laughter because of the heat which arises from the injury" [28]. In fact this "sardonic smile", which is close in meaning to the French "rire jaune", was associated with the diaphragm up to the 19th century. In the Dictionnaire des Sciences Médicales of 1812, Baron Percy, an experienced military surgeon who followed Napoleon's campaigns, described it as a very sensitive clinical sign indicative of a diaphragm wound or rupture [29].

It is important to note that the concept of muscle as a contractile generator of force and movement had still not been developed by Aristotle's time. For Aristotle, muscle was distinguished from other flesh mainly by its consistency. Its function was to keep the animal warm, to protect the bones and other organs from injury, or to hold other tissues together. He thought movements originated in the heart, and were transmitted to the limbs through some sort of mechanical pushing and pulling [30].

Aristotle was also concerned with the problem of the "nature" of respiratory movement, which we would now classify as a problem concerning the breathing control system. His question, which was to be strongly debated throughout the following centuries, was whether breathing was voluntary, like walking, or involuntary, like the heart beat, or alternating between one and the other. His solution was to create a third category called nonvoluntary movement, to encompass sleeping, waking and respiration.

\section{Alexandrian medicine}

After the break-up of Alexander's empire, the centre of culture shifted to Alexandria and flourished under the patronage of the Ptolemies in the 4th and 3rd centuries BC. Medicine made remarkable progress, thanks to an extensive practice of dissection and physiological experimentation, both on animals and, for a few years, on living humans. The two greatest physicians of this period, Herophilus and Erasistratus, redirected the study of respiratory movement by introducing two completely new ideas: the idea of a nervous system with the brain at its centre connected by nerves to the various organs, and the idea of muscle as a force generator.

Since no written works have survived from this period, we must depend for our information on accounts given by Galen and others 400 yrs later. Herophilus is credited with establishing that the brain is the centre of the nervous system and demonstrating the motor and sensory functions of the nerves [31, 32]. Of key importance for the history of the diaphragm, he clearly recognized, for the first time, that muscles were the agents of movement. According to him, movement of the thorax was to be distinguished from movement of the lungs, the first being voluntary, the second involuntary. He also seems to have divided the respiratory cycle into four separate components: expansion of the thorax, expansion of the lungs, contraction of the lungs and contraction of the thorax. These concepts were to show up two centuries later in the teachings of the Roman physician, Asclepiades.

Erasistratus's work on respiration is better known because it is extensively discussed in the profuse writings of Galen, who approved many of his theories but decried others. The vigorous and colourful style of Galen's debate against a long-dead rival makes it difficult to be exactly sure about the position of Erasistratus, but the main features seem clear. He was apparently the first to perform animal experiments that showed that the lungs expand only because muscles expand the thorax [33], experiments that Galen frequently repeated for demonstrations. To explain how the lung is moved by the thorax without any connection between them, he made use of the principle of horror vacui, or filling of void. This was based on the theory that a "connected void", that is an empty space with some shape and volume, could not exist. (Erasistratus did allow a "distributed void", consisting of tiny spaces throughout matter, to help explain phenomena of expansion and contraction or penetration of heat into solids). If material started to leave a space, other material would have to move immediately in behind it, in order to keep the space filled at all times. Distension of the thorax, thus, compelled a flow of air into the thorax to prevent the appearance of an empty space between lung and chest wall. There was much debate on the validity of this concept. The same principle entered into explanations of numerous other physiological and pathological phenomena, including expectoration, but the line of thinking was not always as clearly parallel to a modern concept as it was in the mechanics of breathing [7].

Erasistratus recognized that the diaphragm was a muscle, and taught that it was the main muscle of respiration. His idea about the purpose of air movement was not far from the modern one: although still important for cooling the heart, air also acted as a sort of nutrient, some of it being taken up by the heart and transmitted to the arteries, whence it eventually passed out through the skin.

The Alexandrians founded a great tradition of the study of anatomy and physiology based on detailed dissection and on experimentation, a tradition that was preserved for the next five centuries by a succession of students of Herophilus and Erasistratus in Alexandria and other parts of the Mediterranean world [34]. Although less well-known because little record of their work remains, these people advanced knowledge considerably. In the first century of the modern era, Rufus of Ephesus essentially passed on the discoveries of the Alexandrians. Marinus's 20-volume anatomical work, of which only the table of contents survives, seems to have been a valuable, if disorganised, account. His pupil, Quintus, was an eminent teacher who did not publish but survived in the memories of a large school of followers. One of these, Lycus, wrote his own long treatise on anatomy and physiology, of which the only trace is a withering critique by Galen. Numisianus in Alexandria, Pelops in Smyrna, and Satyrus in Pegamon also left works which have disappeared, but all three 
men were sources for Galen, who recorded their contributions and gave them admiring reviews. The scientific curiosity, the method and the physiological concepts of these men provided the foundation for today's understanding of the mechanics of breathing.

Galen's own first research work on respiration and the voice used experimental methods that he had learned from these predecessors, and were replications or direct extensions of what they had taught about the diaphragm and other muscles of the thoracic cage. He was to synthesize and elaborate on their work to reach an astounding knowledge of the workings of the respiratory pump in the 2 nd century AD.

\section{References}

1. Campbell EJM. The respiratory muscles and mechanics of breathing. London, Lloyd-Lake Ltd, 1958.

2. Jouanna J. Le souffle, la vie, le froid: remarques sur la famille de $\psi v \chi \omega$ d'Homère à Hippocrate. Revue des Etudes Grecques 1987; 99: 203-224.

3. Zafiropulo J. Empedocle d'Agrigente. Les Belles Lettres. Paris, 1953.

4. Leonard WE. The Fragments of Empedocles. Chicago, The Open Court Publishing Company, 1908.

5. Bollack J. Empedocle Les Origines. Les Editions de Minuit. Paris, 1969.

6. Duminil MP. Le sang, les vaisseaux et le coeur dans la Collection Hippocratique. Les Belles Lettres. Paris, 1983.

7. Furley DJ, Wilkie JS. Galen on Respiration and the Arteries. Princeton, Princeton University Press, 1984.

8. Plato. Timaeus. 79. Translation by R.G. Bury, Harvard University Press, 1966.

9. Ibid. 69-71.

10. Hippocrates. Epidemies VI, 2, 3. V 273. Littré.

11. Hippocrates. Epidemies I, II, 682-684. Littré.

12. Grmek MD. Diseases in the Ancient Greek World. Baltimore, Johns Hopkins University Press, 1989.

13. Hippocrates. Diseases. II C.61. II C.47. Translation by F. Adams. Baltimore, Williams \& Wilkins, 1939.
14. Hochberg LA. Thoracic Surgery Before the 20th Century. New York, Vantage Press.

15. Hippocrates. Airs, Waters and Places. English translation by W.H.S. Jones, London and Cambridge, Mass., 1923; (Loeb Classical Library) 22.

16. Jouanna J. Hippocrate. Paris, Fayard, 1992.

17. Hippocrates. The Sacred Disease. Translation by F. Adams. Baltimore, Williams and Wilkins, 1939.

18. Hippocrates. Articulations. English translation by E.T. Whithington. III. London and Cambridge, Mass., 1928, 1968; (Loeb Classical Library) 45.

19. Hippocrates. Epidemies II 4,1. Littré.

20. Hippocrates. Prognostics. 5. Translation by F. Adams, Baltimore, Williams and Wilkins, 1939.

21. Hippocrates. Aphorismes. 18, IV 495. Littré.

22. Hippocrates. Ancient Medicine. English translation by W.H.S. Jones. London and Cambridge, Mass., 1923; (Loeb Classical Library) 22.

23. Franklin KJ. A Short History of Physiology (2nd edn.). Staples, London, 1949.

24. Harris. CRS. The Heart and the Vascular System in Ancient Greek Medicine. Oxford, Oxford University Press, 1973.

25. Aristotle. Parts of Animals. English translation by A.L. Peck. London and Cambridge., Mass., 1937; (Loeb Classical Library) III 6: 669a.

26. Aristotle. Historia Animalium. English translation by A.L. Peck. I-II. London and Cambridge, Mass., 19651970; (Loeb Classical Library) I 17: 4966.

27. Ibid. III $10672 \mathrm{~b}$.

28. Ibid. III 10673.

29. Dictionnaire des Sciences Médicales. Paris, 1812.

30. Bastholm E. The History of Muscle Physiology. Copenhagen, E. Munksgaard, 1950.

31. Solmsen F. Greek Philosophy and Discovery of the Nerves. Museum Helveticum 1961; 18: 151-197. Reproduced in Kleine Schriften Hildesheim. Vol. 1. 19681982; pp. 536-582.

32. Von Staden. H. Herophilus. The art of medicine in early Alexandria. Cambridge, Cambridge University Press, 1989.

33. Galen. On Anatomical Procedures. VIII, II 66 Kuhn.

34. May MT. Galen. On the Usefulness of the Parts of the Body. (Introduction). Ithaca, Cornell University Press, 1984. 